\title{
Pronouncing novel graphemes: The role of consonantal context
}

\author{
STUART E. BERNSTEIN \\ Middle Tennessee State University, Murfreesboro, Tennessee
}

and

\author{
Washington University, St. Louis, Missouri
}

REBECCA TREIMAN

\begin{abstract}
In three experiments, we examined how readers learn and generalize new pronunciations for vowel graphemes. Children ages $6 \frac{1}{2}$ to $9(n=97)$ and college students $(n=21)$ were taught a nonword that included a novel vowel pronunciation in the middle position (e.g., zuop is pronounced/zup/). They were then asked to pronounce other nonwords that contained the same vowel grapheme. Participants were more likely to use the taught pronunciation when the target item and the training item shared a consonant as well as a vowel than when they shared only the vowel. The new pronunciation was not significantly more likely to appear when the target shared the vowel and final consonant (rime) of the training stimulus than when it shared the initial consonant and vowel. We discuss implications for views of reading and its development.
\end{abstract}

English is a difficult writing system to master. Even when a child has learned the basic correspondences between letters and sounds, such as that $b$ corresponds to /b/, much remains to be learned. ${ }^{1}$ For example, the child will encounter groups of letters, such as the digraph $e a$, and must learn that these correspond to single phonemes rather than to sequences of two sounds. Because some digraphs are fairly uncommon, children may not begin to learn about them until they have been reading for some time. In addition, children will come across new pronunciations for known graphemes. Multiple pronunciations of a grapheme are especially common for vowels (Kessler \& Treiman, 2001; Venezky, 1970). For example, ea is pronounced /i/ in meal, /e/ in break, and /e/ in bread. Readers who are familiar with one pronunciation of a grapheme, such as /i/ for ea in meal, will eventually encounter conflicting information, such as /e/ for $e a$ in break. They must learn when each of the different pronunciations of ea is appropriate.

Analyses of English spelling-to-sound correspondences have shown that vowel pronunciation often becomes more predictable when the vowel's context is considered. The consonant(s) that follow a vowel generally improve the pre-

This study was funded by a faculty development grant from Middle Tennessee State University to S.E.B. and Grants SBR-9807736 and BCS-0130763 from the National Science Foundation to R.T. We thank the principals and teachers of Erma Siegel and Northfield elementary schools for their participation. Thanks also to Tara Appelton, Wendy Grubb, Jennifer Hood, Crystal McGee, and Mindy Patterson for their assistance in testing the children. Correspondence concerning this article should be addressed to S. E. Bernstein, Department of Psychology, P. O. Box 87, Middle Tennessee State University, Murfreesboro, TN 37132 (e-mail: sbernst@mtsu.edu). dictability of the vowel's pronunciation more than the consonant(s) that precede it (Kessler \& Treiman, 2001; Treiman, Mullennix, Bijeljac-Babic, \& Richmond-Welty, 1995). Treiman et al. (1995) have suggested that the special status of the postvocalic consonant reflects the internal structure of spoken syllables. According to many linguists (e.g., Fudge, 1969; Goldsmith, 1990; Selkirk, 1982), syllables are not simple strings of phonemes. Rather, syllables are made up of two parts. One constituent is the onset, a frame that contains the initial consonant or consonant cluster. The second constituent is the rime, a frame that contains the vowel and the coda (final consonant or consonant cluster).

Skilled readers of English take advantage of the environment in which a vowel spelling appears to help specify the vowel's pronunciation (e.g., Andrews \& Scarratt, 1998; Treiman, Kessler, \& Bick, 2003; Treiman et al., 1995; Treiman \& Zukowski, 1988). The results of several of these studies suggest that rime context is particularly beneficial. For example, Treiman and Zukowski (1988) examined the generalizations that adults made on the basis of words with unusual pronunciations of vowel graphemes, such as friend. Participants were more likely to extend the $/ \varepsilon /$ pronunciation of ie to nonwords such as chiend, which share its rime with friend, than to nonwords such as frieth, which share the head (onset + vowel), or nonwords such as chieth, which share only the vowel.

Do rimes play a special role for children as well? Rimes appear to be accessible units of spoken words for children, suggesting that corresponding spelling patterns could be important in early reading. In a study by Treiman and Zukowski (1991), 56\% of preschoolers and $74 \%$ of kindergartners could recognize when spoken words shared onsets (e.g., plank and plea) and rimes (e.g., spit and 
wit). Individual phonemes were more poorly recognized. Only $25 \%$ of preschoolers and $39 \%$ of kindergartners successfully judged that pairs of words shared an initial consonant when that consonant was part of a cluster (e.g., steak and sponge). This and other findings (e.g., Goswami \& Bryant, 1990; Kirtley, Bryant, MacLean, \& Bradley, 1989) suggest that awareness of rimes emerges before awareness of individual phonemes.

Goswami $(1986,1988)$ tested beginning readers' ability to use spelling units corresponding to rimes by asking children to pronounce a series of words and nonwords both before and after learning a clue word. Children aged 5-7 were shown how to pronounce clue words like beak and were then asked to pronounce other items. These targets included real words like peak and nonwords like beal. The proportion of targets that were pronounced similarly to the clue word increased after training. The increase was significantly greater for items that shared their rime with the clue word, as for peak with the clue word beak, than for items that shared the head, as for bean with the clue word beak. A shared-rime advantage appeared for both word and nonword targets. The effect was present for all ages tested. These results are consistent with what we call the rime context-first hypothesis. According to this hypothesis, the salience of rimes in speech prepares children to use spelling patterns corresponding to rimes, and children use such patterns from the very beginning of reading development.

Rime effects have also been demonstrated outside the clue-word task. Coltheart and Leahy (1996) created nonwords that could be read by context-free grapheme-tophoneme rules (e.g., jook pronounced as $/ \mathrm{d} 3 \mathrm{uk} /$ ) or in a way that is sensitive to rime context (e.g., jook pronounced as $/ \mathrm{d} z \mathrm{vk} /$, where the vowel grapheme is pronounced as in most other words with oo before $k$ ). Thirdgraders and adults were more influenced by rimes than were first-graders. This finding suggests that rime effects extend beyond the clue-word task (see Bowey, Vaughan, \& Hansen, 1998; Goswami, 1999).

The results of Coltheart and Leahy (1996) suggest that use of rime context increases with reading skill. Further support for this view comes from a study by Brown and Deavers (1999), which used both the nonword pronunciation task and the clue-word task. The critical items in this study were nonwords derived from irregular words (e.g., boup from group). In the nonword pronunciation task, Brown and Deavers found that less skilled readers, a group that included first-graders, produced irregular pronunciations for $38 \%$ of the irregular nonwords. More skilled readers produced these responses for $53 \%$ of the irregular nonwords, close to the adult rate of $58 \%$. Bowey and Hansen (1994) observed a similar increase in the use of orthographic rimes as reading skill increased. According to Goswami (1988; Goswami \& Bryant, 1990; Goswami \& East, 2000), rime influences become larger with age because older children have a larger stock of words that they can use to generate analogies. However, the processes involved in encoding and pronouncing words are the same in younger and older readers, according to Goswami.

Stage models of literacy development (e.g., Frith, 1985; Marsh, Friedman, Welch, \& Desberg, 1981) suggest an alternative explanation for the increase in rime influence with age and reading skill. According to these theories, beginning readers use context-free correspondences between individual graphemes and individual phonemes during the alphabetic stage of reading development. They are not influenced by the consonantal environment in which a vowel appears during translation from spelling to sound. Only during the following stage of development, the orthographic stage, is context used to restrict the application of grapheme-phoneme correspondences. This view, which we label the context-last hypothesis, predicts that the ability to use context to determine pronunciation is tied to a child's overall reading level and cognitive skill. According to data presented by Marsh and colleagues, this ability does not typically emerge until after second grade.

According to the rime context-first hypothesis and the context-last hypothesis, the use of context to determine pronunciation emerges at a particular point in reading development - either early or late — but at the same point for all words. An alternative view is that sensitivity to context emerges at different times for different spelling units, with the differences reflecting children's experiences with the units. This idea stems from Ehri's (1994, 1995) model of literacy development. Context-sensitive spelling-to-sound relationships are consolidations, according to Ehri. They are learned on the basis of patterns that recur in several words, such as -est in nest, rest, test, west, and crest. Spelling can be translated to sound more quickly when the three graphemes in -est are linked and processed as a single unit. Consolidation occurs unit by unit, as readers learn enough words containing particular units to serve as a basis for consolidation. Thus, consolidation is not necessarily restricted to later phases of development. It does tend to be most common after second grade, according to Ehri, when a sizable reading vocabulary has accumulated. This estimate is based on studies that show effects of familiar letter sequences after this point (e.g., Juel, 1983; Leslie \& Thimke, 1986). Ehri's consolidation hypothesis predicts that the sharedrime advantage in the clue-word task depends on age and reading skill to the extent that these variables capture familiarity with families of words that share rimes. When a rime spelling pattern is unfamiliar, however, even skilled readers may not show an advantage for shared rimes over shared heads.

In the present study, we have attempted to distinguish among the rime context-first, context-last, and consolidation hypotheses by teaching children and adults to pronounce "words" that contained novel graphemes and examining how they extended this learning to new items. Unlike previous studies, we did not use rime families that could have been familiar to our participants, such as the -eak of beak and leak. Instead, our training stimuli 
contained unfamiliar spelling patterns that were pronounced in uncommon ways. For instance, participants were taught that zuop is pronounced as /zup/. This training item contains an uncommon grapheme, $u o$, with a pronunciation that it rarely has in English words. The task models a fairly common occurrence in learning to read in English - encountering a new pronunciation for a vowel grapheme and having to learn that pronunciation through experience with a whole word, rather than through direct instruction about the vowel itself. In the training item zuop, the novel grapheme uo appears in a particular consonantal context (preceded by $z$ and followed by $p$ ) and a particular position (the middle of a CVC [consonant-vowel-consonant] nonword). After participants had learned to pronounce the training stimulus, we attempted to infer what they had learned by examining what types of items elicited the taught vowel pronunciation.

If even young children are especially sensitive to rimes, as the rime context-first hypothesis suggests, they should be most willing to extend a newly learned vowel pronunciation to rime neighbors of the training item, such as fuop for the training item zuop. Little transfer should occur when the head is shared or when just the vowel is shared. According to the rime context-first hypothesis, a shared-rime advantage should be found in young children as well as in older children and adults. If the ability to use context to qualify spelling-to-sound relationships develops relatively late in reading development, as the context-last hypothesis suggests, beginning readers should not show a shared-rime advantage. According to this context-last view, only older children and adults should be influenced by the consonantal context in which a vowel grapheme appears. Finally, the consolidation hypothesis suggests that even older children and adults might not show a shared-rime advantage because spelling patterns such as -uop, which do not occur in English words, have not become consolidated.

Our novel grapheme-learning task was modeled on a task that Bernstein and Treiman (2001) developed for spelling. In that earlier study, children learned spellings for nonwords that contained a novel grapheme, such as giik for/gark/. This training item contains a new spelling of /aI/ in a particular consonantal environment (preceded by $/ \mathrm{g} /$ and followed by $/ \mathrm{k} /$ ) and a particular position (the middle of a CVC). Because $i i$ is not a conventional spelling of /aI/ in English, any increase in use of the $i$ spelling after training presumably reflects the training and not previous experience. After children had learned to spell the training item, they were asked to spell a series of target items. Children were more likely to use the novel spelling in targets that shared two phonemes with the training item, such as /gart/ and /vark/ for the training item /gark/, than in targets that shared only the vowel with the training item, such as /vaIm/. No reliable advantage for shared rimes over shared heads was found, not even in second-graders. Children were sensitive to position in that even kindergartners used the novel spelling significantly more often when the vowel was in the same position in the training and target items than when its position differed. For example, when the training item was /gark/, spelled as giik, children used ii significantly more often when /aI/ appeared in the middle of a CVC nonword than when it appeared at the beginning or the end of a nonword.

The findings of Bernstein and Treiman (2001) do not support either the rime context-first hypothesis or the context-last hypothesis. Beginning spellers did use consonantal context in extending the spellings of vowels, but they did not show the significant advantage for shared rimes over shared heads predicted by the rime contextfirst hypothesis. Not even second-graders displayed a rime bias - a preference for the type of context that is most likely to disambiguate vowels in English (Kessler \& Treiman, 2001; Treiman et al., 1995). This outcome could reflect the initial stages of learning about a new grapheme, a result that would be consistent with the consolidation hypothesis. Before accepting this interpretation, however, it is important to determine whether the findings of Bernstein and Treiman are limited to spelling or whether they generalize to reading. In the present study, we developed a reading version of the novel graphemelearning task and used this task with children (Experiments 1 and 2) and adults (Experiment 3).

\section{EXPERIMENT 1}

Children in first, second, and third grades were taught to pronounce a CVC nonword that included a new vowel grapheme. For instance, children learned that the name of a make-believe animal was written as zuop and pronounced as /zup/. Children were then asked to pronounce a series of target items that contained $u o$ in various consonantal contexts and positions. We asked whether children were more likely to use the newly learned correspondence when $u o$ was in the same consonantal context and the same position as in the training stimulus than when it was not.

\section{Method}

Participants. Fifty-seven children from a school in Murfreesboro, Tennessee contributed data. They were native speakers of English and were tested during the second half of the school year. Reading instruction in the children's school followed a whole-language approach, with supplementary phonics instruction (Saxon Publishers, 1996). Twenty-eight first-graders (13 boys and 15 girls) contributed data. They ranged in age from 6 years, 5 months to 8 years, 3 months ( $M=7$ years, 1 month). Four additional first-graders dropped out of the study due to lack of interest and/or experimenter error. We eliminated data from 18 additional first-graders who performed poorly on the catch trials, as explained below, and another firstgrader whose knowledge of letters was very poor. Fourteen secondgraders ( 5 boys and 9 girls) contributed data. They ranged in age from 7 years, 5 months to 8 years, 10 months ( $M=8$ years, 0 months). One additional second-grader dropped out of the study due to lack of interest, and data from 19 other second-graders were eliminated due to poor performance on the catch trials. Fifteen third-graders ( 7 boys and 8 girls) contributed data. They ranged in age from 8 years, 9 months to 9 years, 7 months ( $M=9$ years, 1 month). Data from 11 additional third-graders were dropped due to poor performance on the catch trials. 
Materials. Two CVC nonwords, zuop and neob, were taught in separate sessions. The children were taught to pronounce zuop as /zup/ and neob as /nob/. The $u o-/ \mathrm{u} /$ and $e o-/ \mathrm{o} /$ correspondences are infrequent in English (Cummings, 1988). They occur in a few words (buoy and yeoman), however, and so do not violate basic principles of the system.

We created three sets of seven nonword targets that shared the vowel of each training stimulus. These targets varied in their relationship to the training stimulus. Three targets were CVCs that shared the vowel grapheme of the training stimulus. The CVC target shared the initial consonant as well as the vowel (i.e., the head), the ClV target shared just the vowel, and the CVC target shared the final consonant as well as the vowel (i.e., the rime). In the other four targets, the non-CVC targets, the shared vowel was in a different position than in the training stimulus. The vowel was in the initial position in the VC and VCC items, and in the final position in the $\mathrm{C} \underline{\mathrm{V}}$ and $\mathrm{CC} \underline{\mathrm{V}}$ items. A fourth set of nonword targets was created for the pretest, which was designed to determine how the participants pronounced the critical grapheme prior to training. Finally, nonword filler items were created. The fillers contained a variety of vowels and were included to discourage children from repeating the same vowel pronunciations on all trials. All of the targets were printed in uppercase letters. They are shown in Appendix A.

Procedure. The children were tested individually in a quiet location at their school. All responses were tape-recorded. There were two 10-min sessions with each child, one involving each training stimulus. The order of the sessions was balanced across children. At the beginning of the first session, the uppercase letters of the alphabet were presented in a random order, and the child was asked to say the name and then the sound of each letter. Any child who made more than four errors (out of 52 possible) was dropped from the experiment on the grounds that he or she did not have the basic skill needed to pronounce new printed words.

Each session began with a pretest to determine how children pronounced the critical vowel grapheme prior to training. The experimenter explained to the participants that they would be reading funny animal names aloud, and that the first few names were just for practice. The children were presented with five cards, one at a time, each containing a line drawing of a make-believe animal accompanied by its printed name. The child was asked to read the name of each animal aloud three times. The repetition here and elsewhere in the experiment was intended to encourage children to say the words clearly.

The experimenter then showed the child the training item. This item, introduced as the day's special animal, was presented as a line drawing of a make-believe animal accompanied by its printed name. The experimenter first said the name aloud. The children repeated the name with the experimenter nine times (three times in a normal speaking voice, three times softly, and three times loudly). The children then read the name three times by themselves. After this, the experimenter pointed to the spelling and named each letter aloud. The child pointed to the letters and said their names. In the final part of the training phase, the child pronounced the name of the animal aloud. Each of these tasks was to be repeated if the children made errors, but none of them required any repetitions.

The final part of each session was the test phase. The children were told that they would read the names of other make-believe animals, friends of the day's special animal. The children were asked to pronounce each item three times. The task was conducted in three blocks of 13 trials. The first item in each block was a repetition of the training stimulus. This catch trial served to identify the participants who had not thoroughly learned and remembered the pronunciation of the training stimulus. We eliminated data from the participants who mispronounced the name of the training stimulus in any of the three blocks for either or both of the training stimuli. Although this stringent criterion resulted in the elimination of many participants, as mentioned earlier, it ensured that the remaining children had learned the training items well. Retaining only half the data from a child, when he or she missed one training item but not the other, would have prevented us from using stimulus set as a between-subjects factor in the analyses.

The catch trial was followed by 12 more trials, their order randomized within blocks. In 7 of these trials, a target was presented. Filler items were presented in the remaining 5 trials. A large drawing of the training animal and the spelling of its name were visible during the test phase. The children were reminded about the presence of the training item at the beginning of each block of trials.

\section{Results}

Two individuals transcribed the tape recordings of the experimental sessions. For each response, we determined whether the child pronounced the vowel in the taught manner. The children had pronounced each item three times, and in those rare cases in which pronunciation varied, the more frequent response was counted. Four sessions were selected randomly to assess inter-rater reliability. Disagreements, which occurred for $6.8 \%$ of responses, were discussed and resolved. No disagreements occurred when four additional sessions were subsequently sampled.

The critical vowel digraphs were pronounced in a variety of ways in the pretest. The children sometimes pronounced the digraph as a sequence of two vowel phonemes, as in /ua/ for $u o$, a tendency also observed by Ehri and Soffer (1999); they sometimes pronounced the digraph as it had been taught; and they sometimes pronounced it in other ways. Pretest pronunciations of the digraph with the taught vowel, which occurred $43 \%$ of the time, probably reflected the fact that this vowel is the "long" pronunciation of one letter in the digraph and, for one of the training stimuli, the letter's name. These responses were more frequent than we had observed in a pilot study with adults $(10 \%)$ and probably do not reflect familiarity on the part of children with the uncommon real words containing the taught correspondence. Because the children fairly often pronounced the vowel with the taught correspondence in the pretest, the analyses that we report are based on the percentage change in use of the taught vowel pronunciation from the pretest to the test. ${ }^{2}$ The change scores were computed on an individual basis, separately for each context. The pretest items did not share any consonants with the test items, and so it was appropriate to use the single $\mathrm{CVC}$ item in the pretest as the baseline for the $\underline{\mathrm{CVC}}, \mathrm{CVC}$, and $\mathrm{CVC}$ items. There is thus no possibility of baseline differences affecting our conclusions about items with this structure. The results for participants who responded correctly to all three catch trials are shown in Table 1.

The percentage change scores were analyzed with the between-subjects factor of grade (first, second, third) and the within-subjects factors of target type ( $\underline{\mathrm{CVC}}$, $\mathrm{C} \underline{\mathrm{VC}}, \mathrm{C} \underline{\mathrm{VC}}, \mathrm{C} \underline{\mathrm{V}}, \underline{\mathrm{VC}}, \mathrm{CC} \underline{\mathrm{V}}, \underline{\mathrm{VCC}})$ and set (zuop, neob). There was a significant effect of target type $[F(6,324)=$ $\left.10.520, M S_{\mathrm{e}}=1,458, p<.001\right]$. Also, target type and set interacted $\left[F(6,324)=5.217, M S_{\mathrm{e}}=1,441, p<.001\right]$. No other effects were statistically significant. 
Table 1

Percentage Change in Taught Vowel Pronunciations from Pretest to Test of Experiment 1

\begin{tabular}{|c|c|c|c|c|c|c|c|c|c|c|c|c|c|c|}
\hline \multirow[b]{4}{*}{ Grade } & \multicolumn{14}{|c|}{ Target Type } \\
\hline & \multicolumn{6}{|c|}{$\mathrm{CVC}$} & \multicolumn{8}{|c|}{ non-CVC } \\
\hline & \multicolumn{2}{|c|}{ CVC } & \multicolumn{2}{|c|}{ CㅁC } & \multicolumn{2}{|c|}{$\mathrm{CVC}$} & \multicolumn{2}{|c|}{$\underline{\mathrm{VC}}$} & \multicolumn{2}{|c|}{$\underline{\mathrm{VCC}}$} & \multicolumn{2}{|c|}{$\mathrm{CV}$} & \multicolumn{2}{|c|}{$\mathrm{CC} \underline{\mathrm{V}}$} \\
\hline & $\%$ & $S D$ & $\%$ & $S D$ & $\%$ & $S D$ & $\%$ & $S D$ & $\%$ & $S D$ & $\%$ & $S D$ & $\%$ & $S D$ \\
\hline \multicolumn{15}{|c|}{ zuop set } \\
\hline & \multicolumn{2}{|c|}{ (e.g., zuot) } & \multicolumn{2}{|c|}{ (e.g., ruok) } & \multicolumn{2}{|c|}{ (e.g., fuop) } & \multicolumn{2}{|c|}{ (e.g., uot) } & \multicolumn{2}{|c|}{ (e.g., uond) } & \multicolumn{2}{|c|}{ (e.g., kuo) } & \multicolumn{2}{|c|}{ (e.g., smuо) } \\
\hline First & 56 & 57 & 38 & 52 & 52 & 49 & 26 & 43 & 21 & 11 & 27 & 50 & 9 & 67 \\
\hline Second & 60 & 44 & 50 & 54 & 62 & 49 & -15 & 54 & 33 & 47 & 26 & 49 & 7 & 35 \\
\hline Third & 44 & 48 & 44 & 47 & 49 & 50 & 7 & 52 & 24 & 58 & 13 & 66 & 9 & 53 \\
\hline Mean & 54 & 51 & 43 & 50 & 54 & 49 & 11 & 50 & 25 & 47 & 23 & 54 & 9 & 56 \\
\hline \multicolumn{15}{|c|}{ neob set } \\
\hline & \multicolumn{2}{|c|}{ (e.g., neov) } & \multicolumn{2}{|c|}{ (e.g., peod) } & \multicolumn{2}{|c|}{ (e.g., teob) } & \multicolumn{2}{|c|}{ (e.g., eom) } & \multicolumn{2}{|c|}{ (e.g., eost) } & \multicolumn{2}{|c|}{ (e.g., zeo) } & \multicolumn{2}{|c|}{ (e.g., treo) } \\
\hline First & 39 & 47 & 37 & 47 & 46 & 43 & 30 & 47 & 23 & 44 & 37 & 49 & 35 & 53 \\
\hline Second & 12 & 50 & 0 & 57 & 17 & 43 & 18 & 47 & 12 & 45 & 17 & 47 & 12 & 45 \\
\hline Third & 36 & 71 & 20 & 77 & 33 & 63 & 24 & 57 & 24 & 53 & 4 & 42 & 4 & 38 \\
\hline Mean & 32 & 44 & 23 & 60 & 36 & 50 & 25 & 49 & 20 & 46 & 23 & 48 & 21 & 48 \\
\hline
\end{tabular}

To examine the effect of target type and the interaction of target type and stimulus set, single degree of freedom contrasts were conducted in supplementary analyses of variance (ANOVAs). These analyses were similar to the main ANOVAs, except that the data were collapsed across grades. Analyses were done separately for each stimulus set. The first two comparisons examined the effect of neighboring phonemes in CVC targets. The children showed a significantly greater increase in use of the new pronunciation in targets that shared two phonemes with the training item (the $\underline{\mathrm{CVC}}$ and $\mathrm{CVC}$ items) than in targets that shared one phoneme with the training item (the $\mathrm{C} \underline{\mathrm{VC}}$ items). This was true for both stimulus sets ( $p=$ .006 for zuop; $p<.001$ for neob). Also, for both stimulus sets, the increase in pronunciations that used the new vowel was not significantly greater for items that shared their rimes with the training stimulus (the $\mathrm{CVC}$ items) than for items that shared their heads with the training stimulus (the $\underline{\mathrm{CVC}}$ items).

A third comparison examined whether the children increased more in their use of the new pronunciation when the novel grapheme occurred in the middle of a CVC (i.e., $\underline{\mathrm{CVC}}, \mathrm{CVC}, \mathrm{CVC}$ items), the same position in which it occurred in the training stimuli, than when it occurred in a different position $(\mathrm{C} \underline{\mathrm{V}}, \underline{\mathrm{VC}}, \mathrm{CC} \underline{\mathrm{V}}, \underline{\mathrm{VCC}})$. A significant effect of position was found for the zuop set $(p<$ .001 ). Use of the new pronunciation increased more from pretest to test when the vowel digraph appeared in the middle of a CVC target than when it appeared in either the initial or the final position. For the neob stimulus set, however, the increase in new pronunciations was statistically indistinguishable when the novel grapheme appeared in the medial position of a target and when it appeared in different positions.

Additional analyses showed that the children who failed the catch trials performed differently on the generalization trials than did the children who passed. For neither stimulus set did the children who failed the catch trials show a significant difference between CVC items that shared two graphemes with the target item and those that shared one. As expected, the children who failed the catch trials made significantly more errors on the letter-sound screening task $(M=1.15, S D=1.43)$ than did the children who succeeded on the catch trials $[M=0.56, S D=$ $0.95 ; t(103)=2.506, p=.014]$.

\section{Discussion}

The new pronunciations were difficult for the children to learn, and a number of children did not remember the pronunciations of the training stimuli during the test phase. Therefore, our main analyses included only those children who succeeded in retaining the pronunciations of the training stimuli. We asked how these children generalized from what they were taught and what their generalization patterns revealed about the nature of their learning. If children learned a new grapheme-phoneme correspondence in a context-free manner-learning a correspondence between $u o$ and $/ \mathrm{u} /$ from their experience with the nonword zuop - they should be as likely to generalize this correspondence to ruok (shared vowel) as to fuop (shared rime) and zuot (shared head). This is the pattern of results predicted for beginning readers by the context-last hypothesis. If children learned a correspondence between an orthographic rime and a phonological rime-learning a correspondence between uop and /up/ on the basis of experience with zuop - they should be more likely to generalize to fuop (shared rime) than to either zuot (shared head) or ruok (shared vowel). This is the pattern of results predicted by the rime context-first hypothesis.

Our data did not fit either of the two patterns just described. Instead, children were more likely to use the taught vowel pronunciation when either the following consonant or the preceding consonant in a CVC matched that of the training item. Whether the shared consonant came before the vowel or after the vowel was immater- 
ial. The pattern of results was the same at all three grade levels. Children who did not pass the catch trials did not show this pattern of generalization, instead showing similar rates of taught pronunciations in all contexts.

The results of Experiment 1 do not support the idea that young children learn context-free correspondences between single graphemes and single phonemes from their exposure to novel words, generalizing these correspondences in a way that does not take context into account (Frith, 1985; Marsh et al., 1981). Nor do the results support the idea that children rely primarily on correspondences between orthographic rimes and phonological rimes from the beginning of reading development, as the rime context-first hypothesis predicts (Goswami, 1986, 1988). Our results suggest that context does play a role in children's learning and transfer of vowel pronunciations. For medial vowels, transfer is more likely if one of the surrounding consonants is shared than if neither consonant is shared. However, there is no special priority for a shared rime, even for third-graders. These results may reflect the initial learning of a new grapheme, one that has not had a chance to become consolidated with the graphemes that typically accompany it. We will discuss the pattern of results with respect to the consolidation hypothesis in the General Discussion section.

The effects of consonantal context were consistent across the two sets of stimuli. The effects of position were less clear. A pronunciation that was learned in the middle of a CVC was not always used more often when it occurred in the middle of another CVC than when it occurred in syllable-initial or syllable-final position. Because an effect of shared position was not present in both of our stimulus sets, and because there were some differences in the base rate of the taught pronunciations across contexts, we cannot draw strong conclusions about the effect of positional context on vowel pronunciation.

\section{EXPERIMENT 2}

The lack of a shared-rime advantage even for the more experienced readers of Experiment 1 was surprising in light of previous studies that have pointed to an important role for rime units in the pronunciation of English words and nonwords (e.g., Andrews \& Scarratt, 1998; Treiman et al., 1995; Treiman \& Zukowski, 1988). We designed Experiment 2 to test the robustness and generality of the Experiment 1 results. The novel graphemelearning task was modified in several ways. One change was the use of words with context-conditioned pronunciations instead of nonwords for the filler items. Brown and Deavers (1999) suggested that the inclusion of nonwords in a list encourages readers to use correspondences between print and speech at the level of single graphemes and single phonemes (see also Monsell, Patterson, Graham, Hughes, \& Milroy, 1992). On the basis of this suggestion, it is possible that larger units, including rimes, might become more prominent if real words such as mind and move were used as fillers. Such words cannot be read correctly on the basis of context-free correspondences between single graphemes and single phonemes.

Several additional changes were made in an attempt to improve the children's learning of the novel items. The training procedure was lengthened to include spelling of the novel item from memory. Also, the retention interval was shortened. Another change was an increase in the number of training stimuli from 2 to 10 . This change allowed items to be treated as a random factor in the analyses, which was not possible in Experiment 1. Increasing the number of training stimuli to 10 also allowed us to drop blocks linked to items missed on the catch trials rather than all data from a participant who missed a catch trial, which was necessary when there were only 2 training sets.

To compensate for the increase in the number of training items, only test items with the vowel in the medial position were included. This allowed for a more careful measurement of the effect of phonemes surrounding a vowel, keeping the syllabic structure of the test items constant. We collected pretest pronunciations of all graphemes and, for each participant, dropped results on items for which he or she pronounced the vowel grapheme in the intended fashion before training. To minimize the number of such responses on the pretest, we included more cases in which the trained pronunciation of the vowel digraph was not the name of either letter. Finally, we collected reading achievement test scores from the children.

\section{Method}

Participants. Forty children from a school in Murfreesboro, Tennessee contributed data. All were native speakers of English, and none had participated in Experiment 1. Reading instruction followed the same program as for the children in Experiment 1. The children were tested in the first half of the school year. Nineteen second-graders ( 11 boys and 8 girls) contributed data. They ranged in age from 7 years, 4 months to 9 years, 2 months ( $M=7$ years, 10 months). Three additional second-graders dropped out of the study due to lack of interest. Twenty-one third-graders ( 6 boys and 15 girls) contributed data. They ranged in age from 7 years, 5 months to 8 years, 10 months ( $M=8$ years, 4 months). One additional third-grader dropped out of the study due to lack of interest. Mean percentile scores on the Terra Nova reading achievement test (CTB McGraw-Hill, 2000), which had been given at the end of the previous school year to all but 5 of the children, were 71 for secondgraders $(S D=19)$ and 70 for third-graders $(S D=14)$, typical scores for this school district.

Materials. The training stimuli were $10 \mathrm{C}(\mathrm{C}) \mathrm{VC}$ nonwords containing vowel digraphs that were pronounced with correspondences that occur in relatively few English words (Cummings, 1988). Each digraph was incorporated into one training stimulus. For instance, ie was pronounced $/ \varepsilon /$ in siep. In most cases, the training stimuli did not share their rimes or their heads with any real word that included the correspondence. For example, siep does not share its rime or head with friend. For each training stimulus, we constructed a $\underline{\mathrm{CVC}}$ target that shared the initial consonant (or cluster) as well as the vowel of the training stimulus, a C $\underline{\text { C }}$ target that shared just the vowel, and a C $\underline{\mathrm{VC}}$ target that shared the final consonant as well as the vowel. A fourth stimulus shared only its vowel with the training stimulus and was used as the pretest item. Appendix B shows the 10 groups of stimuli. These were divided into two sets of five, and each set was used for one day of testing. The order of the sets was balanced across participants. 
Procedure. The children were tested in two 10-min sessions in a quiet location. All responses were tape-recorded. Each session began with the pretest items. The children were asked to pronounce each pretest item three times in a row, using the same pronunciation each time. Each nonword was presented as the name of a makebelieve animal along with a line drawing of the animal. Five blocks of experimental trials were then conducted.

Each block began with learning the name of the special animal, the training stimulus. The training item was presented as a line drawing of a make-believe animal accompanied by its printed name. The experimenter first said the name aloud. The children then repeated the name with the experimenter nine times (three times in a normal speaking voice, three times softly, and three times loudly). The children then read the name three times by themselves. After this, the experimenter pointed to the spelling of the name of the animal and named each letter aloud. The word was removed from view, and the children spelled the training item from memory. In the final part of the training phase, the children read the name of the animal aloud. Each of these tasks was to be repeated if the children made errors, but no child required any repetitions.

As in Experiment 1, a picture of the special animal and its printed name remained visible when the children read the names of its friends during the test phase. In each block of trials, the three neighbors were presented along with the three filler items. The items were in a different random order for each participant. Each block of trials ended with a catch trial in which the training item was presented.

\section{Results}

One individual transcribed the tape recordings, determining whether the vowel was pronounced as in the training stimulus. The children had pronounced each item three times. In the rare cases in which pronunciation varied, the more frequent response was counted. We eliminated data from blocks in which the catch item was not pronounced as taught $(M=23 \%$ of trials, $S D=14)$ and data from trials in which the participant had pronounced the pretest item with the taught vowel $(M=10 \%, S D=$ $10)$. Table 2 shows the percentage of the remaining responses that used the taught vowel pronunciations.

Two ANOVAs were conducted in which grade (second, third) served as a between-subjects factor and target type ( $\underline{\mathrm{CVC}}, \mathrm{C} \underline{\mathrm{VC}}, \mathrm{CVC})$ served as a within-subjects factor. In the first ANOVA $\left(F_{1}\right)$ participants were the random factor, and in the second ANOVA $\left(F_{2}\right)$ items were the random factor. The rate of taught vowel pronunciations varied significantly as a function of target type $\left[F_{1}(2,76)=8.498, M S_{\mathrm{e}}=249, p<.001 ; F_{2}(2,36)=\right.$ 8.394, $\left.M S_{\mathrm{e}}=157, p<.001\right]$. Grade had no significant effect. A planned comparison showed that the children were significantly more likely to use the taught vowel

Table 2

Percentage of Responses in Test Phase of Experiment 2 Using Taught Vowel Pronunciations for Second- and Third-Graders

\begin{tabular}{|c|c|c|c|c|c|c|}
\hline \multirow[b]{3}{*}{ Grade } & \multicolumn{6}{|c|}{ Target Type } \\
\hline & \multicolumn{2}{|c|}{$\underline{\mathrm{CVC}}$} & \multicolumn{2}{|c|}{ C $\underline{\mathrm{C}}$} & \multicolumn{2}{|c|}{$\mathrm{CVC}$} \\
\hline & $\%$ & $S D$ & $\%$ & $S D$ & $\%$ & $S D$ \\
\hline Second & 74 & 22 & 58 & 23 & 75 & 25 \\
\hline Third & 66 & 25 & 59 & 24 & 69 & 24 \\
\hline Mean & 69 & 23 & 58 & 23 & 72 & 24 \\
\hline
\end{tabular}

pronunciation in items that shared two phonemes with the training item, the $\mathrm{CVC}$ and $\mathrm{CVC}$ items $(M=71$, $S D=24)$, than in items that shared one phoneme with the training item, the C $\underline{V} \mathrm{C}$ items $(M=58, S D=23)$ $\left[F_{1}(1,38)=17.357, M S_{\mathrm{e}}=356, p<.001 ; F_{2}(1,18)=\right.$ $\left.20.015, M S_{\mathrm{e}}=194, p<.001\right]$. Another planned comparison showed that children were not significantly more likely to use the taught vowel pronunciation in items that shared their rimes with the training stimulus, the CVC targets, than in items that shared their initial consonant and vowel with the training stimulus, the $\underline{\mathrm{CVC}}$ targets $\left(F_{1}<1 ; F_{2}<1\right)$. The pattern of results was the same when we analyzed the data from the 8 best third-grade readers in the study; these were children who scored above the 89th percentile on the standardized reading test.

As in Experiment 1, a final analysis was conducted to determine whether failure on the catch trials actually indicated a difference in performance. In blocks where participants failed the catch trials, there were no significant differences in the use of the taught pronunciation across contexts. This was different from the significant context effects when the catch trials were passed.

\section{Discussion}

In Experiment 2, we modified the nonword pronunciation task of Experiment 1 to further study children's use of consonantal context in the learning and transfer of new vowel pronunciations. The stimulus set included 10 items, allowing us to determine the stability of effects across both items and participants. Prior knowledge of the intended pronunciation was assessed with a pretest. Learning of the training items was measured by catch trials. These procedures allowed us to be fairly certain that children had learned and retained the intended pronunciations and that use of these pronunciations after training was due to the training in the experiment rather than to previous experience.

The effects of consonantal context that were found in Experiment 1 were replicated with the expanded stimulus set. Children who were taught a new pronunciation, such as /zæm/ for zaum, were more willing to extend this pronunciation to items that shared a consonant as well as a vowel with the training item (e.g., zaun, taum) than to items that shared only the vowel (e.g., haub). This effect was stable across participants and items. As in Experiment 1 , we did not observe a reliable shared-rime advantage. Children were not significantly more likely to extend the new pronunciation to targets that shared their VCs with the training item than to targets that shared their $\mathrm{CV}$ s with the training item. There was no significant advantage for shared rimes over shared heads among the third-graders as a group or among the most skilled thirdgrade readers. Recall that the filler items in Experiment 2 were real words that could only be pronounced correctly if participants used context. For instance, a context-free pronunciation of have would yield /hev/, which is incorrect. This was different than in Experi- 
ment 1 , where the fillers as well as the critical stimuli were nonwords. Although the change in the nature of the filler items might have been expected to increase readers' reliance on context in pronunciation (Brown \& Deavers, 1999; Monsell et al., 1992), it did not cause a sharedrime advantage to emerge.

In Experiment 3, we examined the performance of skilled adult readers in the novel grapheme learning task. The third-graders in Experiment 2 did not show a reliable advantage for shared rimes over shared heads when pronouncing targets that overlapped with the training items. However, it is possible that this effect emerges at some point after the third grade. Experiment 3 was carried out to determine whether college students would show a shared-rime advantage.

\section{EXPERIMENT 3}

\section{Method}

Participants. Twenty-one undergraduate students from Middle Tennessee State University participated in exchange for extra credit in their introductory psychology classes. All were native speakers of English.

Materials and Apparatus. Stimuli were identical to those of Experiment 2. Stimuli were presented and responses recorded on a computer under the control of E-Prime Version 1.0 (Psychology Software Tools, 2000). As in Experiments 1 and 2, the items were presented individually, but the line drawings of make-believe animals were not used.

Procedure. The participants were tested in a single 20 -min session. All responses were tape-recorded. The pretest, training, and test trials were conducted similarly to Experiment 2, except that the computer was used to present the spoken and printed words, and the training item was not visible during the test trials.

\section{Results}

One individual transcribed the tape recordings, determining whether the participants used the vowel that was taught in the training stimulus. In the rare cases in which pronunciation of the vowel varied across the three pronunciations of an item, the more frequent response was counted. Data were eliminated from blocks in which the catch item was not pronounced as taught $(M=38 \%$ of trials, $S D=22$ ). Data were also eliminated from trials in which the participants pronounced the pretest item with the vowel that was to be taught $(M=4 \%, S D=5)$.

The adults used the taught vowel pronunciation $65 \%$ of the time $(S D=29)$ with the $\underline{C V C}$ items, $47 \%$ of the time with the CVC items $(S D=32)$, and $68 \%$ of the time $(S D=21)$ with the CVC items. In ANOVAs using target type ( $\underline{\mathrm{CVC}}, \mathrm{C} \underline{\mathrm{VC}}, \mathrm{C} \underline{\mathrm{VC}})$ as a within-subjects factor, the rate of taught vowel pronunciations varied significantly as a function of target type $\left[F_{1}(2,40)=6.315, M S_{\mathrm{e}}=\right.$ $\left.426, p<.01 ; F_{2}(2,18)=4.234, M S_{\mathrm{e}}=166, p<.05\right]$. A planned comparison showed that the adults were significantly more likely to use the taught vowel pronunciation in items that shared two phonemes with the training item, the $\underline{\mathrm{CVC}}$ and $\mathrm{CVC}$ items $(M=67, S D=25)$, than in items that shared one phoneme with the training item, the C $\underline{V}$ items $(M=47, S D=32)\left[F_{1}(1,20)=11.946\right.$,
$M S_{\mathrm{e}}=668, p<.01 ; F_{2}(1,9)=19.666, M S_{\mathrm{e}}=100, p<$ $.01]$. Another planned comparison showed that adults were not significantly more likely to use the taught vowel pronunciation in items that shared their rimes with the training stimulus, the $\mathrm{CVC}$ targets, than in items that shared their initial consonant and vowel with the training stimulus, the $\underline{\mathrm{CVC}}$ targets $\left(F_{1}<1 ; F_{2}<1\right)$.

\section{Discussion}

The effects of consonantal context that were found in children in Experiments 1 and 2 were replicated with adults. After learning to pronounce a nonword with a relatively infrequent pronunciation of a vowel grapheme, as with /zæm/ for zaum, adults were more willing to extend this pronunciation to items that shared a consonant as well as a vowel with the training item (e.g., zaun or taum) than items that shared only the vowel (e.g., haub). This effect was stable across participants and items. The adults, like the children of Experiments 1 and 2, did not show a significant advantage for shared rimes over shared heads. Adults were no more likely to extend the new pronunciation to targets that shared their VCs with the training item than to targets that shared their CVs with the training item.

\section{GENERAL DISCUSSION}

Children who are learning to read in English must deal with letters and letter groups that are pronounced in more than one way. Such one-to-many mappings from spelling to sound are especially common for vowels. For example, ea corresponds to /i/ in meal, /e/ in break, and $/ \varepsilon /$ in bread. Do children take advantage of the context in which a grapheme occurs as a way of coping with the diversity of print-to-sound relationships? We used a novel grapheme learning task to address this question. Children and adults were taught a new "word" that contained an infrequent pronunciation of a vowel grapheme in a novel orthographic context. We asked how often participants used the new pronunciation when the context of the grapheme varied in other items.

Participants who learned, for example, that $u o$ is pronounced as $/ \mathrm{u} /$ in zuop were influenced by the identity of the neighboring consonants when they extended the $/ \mathrm{u} /$ pronunciation of $u o$ to other items. They were more likely to use newly learned pronunciation in targets that shared a consonant as well as a vowel with the training item than in targets that shared only their vowel with the training item. At none of the age levels or reading levels that we studied did we observe significantly more transfer when the rime was shared than when the head was shared.

Our finding that even beginning readers are influenced by consonantal context when learning and extending vowel correspondences does not fit with the context-last hypothesis. In that view, young children rely on context-free associations between graphemes and phonemes (e.g., Frith, 1985; Marsh et al., 1981). Nor do our results fit with the rime context-first hypothesis 
(e.g., Goswami, 1986, 1988). We found no shared-rime advantage in young children. Indeed, contrary to some previous findings (e.g., Treiman \& Zukowski, 1988), we found no shared-rime advantage in adults. The pattern of results - more generalization when a consonant and a vowel were shared than when only a vowel was sharedwas remarkably independent of age and reading ability. Importantly, this is the same outcome that Bernstein and Treiman (2001) found for spelling.

Why did both children and adults use context in such a broad and indiscriminate way? This pattern may reflect the fact that our study, unlike previous studies, focused on an early point in the learning of a spelling-sound correspondence. A participant in our experiments who learned that zuop was pronounced as /zup/ was encountering the spelling patterns -uop and zuo- for the first time. These spelling patterns were not repeated often enough in the experiment to become very familiar. Under these circumstances, no advantage for shared rimes over shared heads was found in the present reading study or in the previous study of spelling (Bernstein \& Treiman, 2001). This pattern of results is consistent with the consolidation hypothesis (Ehri, 1994, 1995). The results suggest that a shared-rime advantage, when it is observed, reflects the consolidation of recurring spelling patterns. It does not reflect an intrinsic bias to use rimes in making analogies between new items and old ones. Under that scenario, we should have seen an advantage for shared rimes over shared heads even with unfamiliar rimes.

Our results suggest a memory-based view of the learning of correspondences between spellings and sounds. When readers learn a new pronunciation for a grapheme, they must often overcome some existing knowledge. For example, learning that zuop is pronounced as /zup/ requires readers to overcome the tendency to pronounce a sequence of two vowel letters as a sequence of two phonemes, such as $/ \mathrm{ua} /$. . A new item that contains $u o$ will remind the reader of zuop to the extent that it resembles zuop. Items such as zuot and fuop, which share three letters with zuop, will thus give rise to more $/ \mathrm{u} /$ pronunciations than items such as ruok, which share two letters. In this view, the visual similarity between a new item and an item that is stored in memory is the main determinant of transfer during the early stages of learning about a new correspondence. This reflects basic processes about memory - the influence of similarity in calling up an item stored in memory (e.g., Nosofsky, 1988) —rather than linguistic factors. Given these memory factors, context plays a role in the initial learning of a new correspondence, both for adults and children.

If learners encounter a new grapheme several times in the same context, as with $e$ in nest, rest, and test, they begin to treat the grapheme and the letters that typically accompany it as a unit. In Ehri's $(1994,1995)$ terms, they begin to consolidate the spelling pattern. Across the English language as a whole, this process is more likely to occur for rimes than for heads, a difference that reflects the characteristics of the English vocabulary. Spelling patterns such as -est and -et occur in many words, whereas those like -ep do not. In contrast, the distribution of head patterns is more uniform (Kessler \& Treiman, 1997; Treiman et al., 1995). This fact may promote the unitization of certain rime spelling patterns and may cause rimes, as a whole, to show more consolidation than heads. Learners who encounter a grapheme in several words also have the opportunity to learn whether and how its pronunciation is associated with its context. For example, children who experience $e a$ in a variety of words can learn that its pronunciation tends to differ when the coda is $d$ (e.g., head, dead) versus $m$ (e.g., seam, dream). Because the pronunciations of vowels are more likely to be affected by the consonants that follow them than by the consonants that precede them (Kessler \& Treiman, 2001; Treiman et al., 1995), rime units come to be more useful in spelling-to-sound translation, overall, than heads. However, people's broad sensitivity to context during the early stages of learning about a new correspondence allows them to pick up those associations that cross the onset-rime boundary. For example, readers learn that the pronunciation of $a$ tends to differ as a function of whether the preceding letter is $u$ or $w$ (e.g., squat, wand) or another consonant (e.g., pat, hand; Treiman et al., 2003). Spellers also learn about onset-to-vowel associations (Treiman, Kessler, \& Bick, 2002). In this view, consolidation emerges unit by unit, depending more on learners' experience with a particular unit than on their age or overall level of literacy development. The characteristics of the English vocabulary and the nature of its writing system generally favor the consolidation of vowels and final consonants, but initial consonants and vowels can be linked as well. In the present study, units such as -uop were not presented often enough or in enough different words to permit consolidation to occur. In future work, it will be important to examine the kinds of experiences that allow this to happen.

The present results, together with the results of Bernstein and Treiman (2001), show that children and adults behave in a remarkably similar manner when they implicitly learn a new correspondence between spelling and sound. In the initial stages of learning, both groups use context in a broad and indiscriminate way as they extend the newly learned correspondence. The results do not support the idea that young children are insensitive to the contexts in which graphemes and phonemes occur (e.g., Marsh et al., 1981). Nor do the results support the idea that phonological and orthographic rimes play a special role from the very beginning of reading and spelling development (e.g., Goswami, 1986, 1988). Rather, we suggest, the patterns of generalization that occur during the learning of a new correspondence reflect basic properties of memory. As these interact with the structure of the English vocabulary and the characteristics of the writing system, a bias toward rime context sometimes, but not always, emerges. 


\section{REFERENCES}

Andrews, S., \& ScarratT, D. R. (1998). Rule and analogy mechanisms in reading nonwords: Hough dou peapel rede gnew wirds? Journal of Experimental Psychology: Human Perception \& Performance, 24, 1052-1086.

Bernstein, S. E., \& Treiman, R. (2001). Learning a novel grapheme: Effects of positional and orthographic context on children's spelling. Journal of Experimental Child Psychology, 79, 56-77.

BoweY, J. A., \& HANSEN, J. (1994). The development of orthographic rimes as units of word recognition. Journal of Experimental Child Psychology, 58, 465-488.

BoweY, J. A., VAUGHAN, L., \& Hansen, J. (1998). Beginning readers' use of orthographic analogies in word reading. Journal of Experimental Child Psychology, 68, 108-133.

Brown, G. D. A., \& Deavers, R. P. (1999). Units of analysis in nonword reading: Evidence from children and adults. Journal of Experimental Child Psychology, 73, 208-242.

Coltheart, V., \& Leahy, J. (1996). Procedures used by beginning and skilled readers to read unfamiliar letter strings. Australian Journal of Psychology, 48, 124-129.

CTB McGraW-HiLl (2000). Terra Nova. Monterey, CA: Author.

Cummings, D. W. (1988). American English spelling. Baltimore: Johns Hopkins University Press.

EHRI, L. C. (1994). Development of the ability to read words: Update. In R. B. Ruddell, M. R. Rudell, \& H. Singer (Eds.), Theoretical models and processes of reading (4th ed., pp. 323-358). Newark, DE: International Reading Association.

EHRI, L. C. (1995). Phases of development in learning to read words by sight. Journal of Research in Reading, 18, 116-125.

EHRI, L. C., \& Soffer, A. G. (1999). Graphophonemic awareness: Development in elementary students. Scientific Studies of Reading, $\mathbf{3}, 1$ 30.

Frith, U. (1985). Beneath the surface of developmental dyslexia. In K. E. Patterson, J. C. Marshall, \& M. Coltheart (Eds.), Surface dyslexia: Neuropsychological and cognitive studies of phonological reading (pp. 301-330). London: Erlbaum.

FUdGE, E. (1969). Syllables. Journal of Linguistics, 5, 253-287.

Goldsmith, J. (1990). Autosegmental and metrical phonology. Oxford: Blackwell.

Goswami, U. (1986). Children's use of analogy in learning to read: A developmental study. Journal of Experimental Child Psychology, $\underline{\mathbf{4 2}}$, 73-83.

GosWAMI, U. (1988). Orthographic analogies and reading development. Quarterly Journal of Experimental Psychology, 40A, 239-268.

GoswamI, U. (1999). Orthographic analogies and phonological priming: A comment on Bowey, Vaughan, and Hansen (1998). Journal of Experimental Child Psychology, 72, 210-219.

Goswami, U., \& Bryant, P. E. (1990). Phonological skills and learning to read. Hillsdale, NJ: Erlbaum.

Goswami, U., \& EAST, M. (2000). Rhyme and analogy in beginning reading: Conceptual and methodological issues. Applied Psycholinguistics, 21, 69-93.

International Phonetic Association (1996). Reproduction of the International Phonetic Alphabet. Available at http://www2.arts.gla. ac.uk/IPA/ipachart.html.

InTERNATIONAL PHONETIC Association (1999). Handbook of the International Phonetic Association: A guide to the use of the International Phonetic Alphabet. Cambridge: Cambridge University Press.

Juel, C. (1983). The development and use of mediated word identification. Reading Research Quarterly, 18, 306-327.
Kessler, B., \& Treiman, R. (1997). Syllable structure and the distribution of phonemes in English syllables. Journal of Memory \& Language, 37, 295-311.

KesSLER, B., \& TREIMAN, R. (2001). Relationships between sounds and letters in English monosyllables. Journal of Memory \& Language, 44, 592-617.

KiRTLey, C., Bryant, P., Maclean, M., \& Bradley, L. (1989). Rhyme, rime, and the onset of reading. Journal of Experimental Child Psychology, 48, 224-245.

LESLIE, L., \& THIMKE, B. (1986). The use of orthographic knowledge in beginning reading. Journal of Reading Behavior, 18, 229-241.

Marsh, G., Friedman, M., Welch, V., \& Desberg, P. (1981). A cognitivedevelopmental theory of reading acquisition. In G. E. MacKinnon \& T. G. Waller (Eds.), Reading research: Advances in theory and practice (Vol. 3, pp. 199-221). New York: Academic Press.

Monsell, S., Patterson, K. E., Graham, A., Hughes, C. H., \& MilROY, R. (1992). Lexical and sublexical translation of spelling to sound: Strategic anticipation of lexical status. Journal of Experimental Psychology: Learning, Memory, \& Cognition, 18, 452-467.

NosofsKy, R. M. (1988). Exemplar-based accounts of relations between classification, recognition, and typicality. Journal of Experimental Psychology: Learning, Memory, \& Cognition, 14, 700-708.

Psychology Software Tools (2000). E-Prime 1.0. Pittsburgh, PA: Author.

SAXON PUblishers (1996). Saxon phonics. Norman, OK: Author.

SELKIRK, E. O. (1982). The syllable. In H. van der Hulst \& N. Smith (Eds.), The structure of phonological representations (Part II, pp. 337383). Dordrecht: Foris.

Treiman, R., Kessler, B., \& Bick, S. (2002). Context sensitivity in the spelling of English vowels. Journal of Memory \& Language, 47, 448468.

Treiman, R., Kessler, B., \& BicK, S. (2003). Influence of consonantal context on the pronunciation of vowels: A comparison of human readers and computational models. Cognition, 88, 49-78.

Treiman, R., Mullennix, J., Bijeljac-Babic, R., \& Richmond-Welty, E. D. (1995). The special role of rimes in the description, use, and acquisition of English orthography. Journal of Experimental Psychology: General, 124, 107-136.

TrEIMAN, R., \& ZUKOWSKI, A. (1988). Units in reading and spelling. Journal of Memory \& Language, 27, 466-477.

TrEIMAN, R., \& ZuKOWSKI, A. (1991). Levels of phonological awareness. In S. A. Brady \& D. P. Shankweiler (Eds.), Phonological processes in literacy: A tribute to Isabelle Y. Liberman (pp. 67-83). Hillsdale, NJ: Erlbaum.

VENEZKY, R. L. (1970). The structure of English orthography. The Hague: Mouton.

\section{NOTES}

1. Phonemes are represented using the alphabet of the International Phonetic Association (1996, 1999). Conventional spellings are given in italics and pronunciations in IPA symbols surrounded by slash marks. The values of most IPA symbols agree with those of the corresponding English letter, but the following require special attention: /ar/aisle, /æ/ apple, /a/ odd, /dz/ jump, /e/ ape, /e/ edit, /i/ eat, /I/ hip, /o/ oat, /o/ dawn, /u/ rude, / / $/ \boldsymbol{u g l y}$, and / $/$ put.

2 . The key result - significantly more pronunciations with the taught vowel when two graphemes were shared than one, but no significant superiority for shared rimes over shared heads - was also found in analyses that were restricted to children who never used the taught pronunciation in the pretest. 
APPENDIX A

Experiment 1: Stimuli

\begin{tabular}{|c|c|c|c|c|c|c|c|}
\hline Condition & $\underline{\mathrm{CVC}}$ & $\mathrm{C} \underline{\mathrm{V}} \mathrm{C}$ & $\mathrm{C} \underline{\mathrm{VC}}$ & $\underline{\mathrm{VC}}$ & $\underline{\mathrm{VCC}}$ & $\mathrm{C} \underline{\mathrm{V}}$ & $\mathrm{CC} \underline{\mathrm{V}}$ \\
\hline \multicolumn{8}{|c|}{ zuop set } \\
\hline Pretest & - & vuok & - & uon & uots & fuo & pluo \\
\hline \multirow[t]{3}{*}{ Test } & zuot & ruok & fuop & uot & uond & kuo & sтио \\
\hline & zuok & tuod & ruop & uod & uost & vuo & snuo \\
\hline & zuon & kuov & пиор & uok & uoms & ruo & fruo \\
\hline \multicolumn{8}{|c|}{ Fillers: zaip, zoam, teap, voon, ree, snea, eeb, aind, zep, zub, bap, lut, ak, og, unt } \\
\hline \multicolumn{8}{|c|}{ neob set } \\
\hline Pretest & - & zeom & - & eop & eods & тео & pleo \\
\hline \multirow[t]{3}{*}{ Test } & neov & peod & teob & eom & eost & $z e o$ & treo \\
\hline & neok & feot & $z e o b$ & $e o z$ & eont & keo & smeo \\
\hline & neof & deok & veob & eov & eoft & veo & dreo \\
\hline \multicolumn{8}{|c|}{ Fillers: naib, noax, leab, zeen, fai, snoo, eep, oots, neb, nop, mib, lat, ig, ap, ats } \\
\hline
\end{tabular}

APPENDIX B

Experiment 2: Stimuli

\begin{tabular}{|c|c|c|c|c|c|c|c|c|c|}
\hline Grapheme & Pronunciation & Training & Pretest & $\underline{\mathrm{CVC}}$ & C므 & $\mathrm{CVC}$ & Filler 1 & Filler 2 & Filler 3 \\
\hline \multicolumn{10}{|c|}{ Set A } \\
\hline$a u$ & $/ \mathfrak{a} /$ & zaum & dauz & zaun & haub & taum & been & long & move \\
\hline$e a$ & /e/ & feag & keaf & feap & teab & neag & $d w a r f$ & mind & watch \\
\hline$e o$ & /o/ & neob & peod & neok & deok & teob & comb & gone & swap \\
\hline$o a$ & $/ 2 /$ & snoap & gloak & snoak & floab & troap & bowl & climb & foot \\
\hline uo & $/ \mathrm{u} /$ & tuop & muоj & tuok & zuod & ruop & boss & squash & want \\
\hline \multicolumn{10}{|c|}{ Set B } \\
\hline$a e$ & /i/ & naek & zaet & naeb & vaep & yaek & give & swam & wolf \\
\hline$a i$ & /aI/ & raich & baish & raist & daisk & taich & book & calm & wand \\
\hline$i e$ & $/ \varepsilon /$ & siep & nieb & sief & biez & miep & front & honk & wash \\
\hline ou & $/ \Lambda /$ & glouf & brout & gloup & prouk & trouf & shoe & swamp & warm \\
\hline$u i$ & $/ \mathrm{I} /$ & vuib & ruiv & vuip & duit & tuib & cloth & have & love \\
\hline
\end{tabular}

(Manuscript received June 11, 2003;

revision accepted for publication January 19, 2004.) 